Association for Information Systems AIS Electronic Library (AISeL)

ECIS 2000 Proceedings

European Conference on Information Systems

(ECIS)

2000

\title{
Bundling Strategy in Base Supplemental Goods Markets: The Case of Microsoft
}

Sang-Yong Tom Lee

National University of Singapore

Follow this and additional works at: http://aisel.aisnet.org/ecis2000

\section{Recommended Citation}

Lee, Sang-Yong Tom, "Bundling Strategy in Base Supplemental Goods Markets: The Case of Microsoft" (2000). ECIS 2000 Proceedings. 86.

http://aisel.aisnet.org/ecis2000/86

This material is brought to you by the European Conference on Information Systems (ECIS) at AIS Electronic Library (AISeL). It has been accepted for inclusion in ECIS 2000 Proceedings by an authorized administrator of AIS Electronic Library (AISeL). For more information, please contact elibrary@aisnet.org. 


\title{
Bundling Strategy in Base-Supplemental Goods Markets: The Case of Microsoft
}

\author{
Sang-Yong Tom Lee \\ National University of Singapore \\ 3 Science Drive 2, Singapore 117543
}

\begin{abstract}
We show that bundling is the optimal pricing strategy for a base good monopolist who also supplies a supplemental good under zero marginal cost of production. Without the exit of the rival firm, bundling is a profitable strategy because it increases the profits in the base good market. We show that bundling lowers social welfare as well as rival firms' profit if the supplemental goods are close substitutes. Otherwise, bundling may actually generate welfare enhancements. Our analysis applies directly to the computer software markets and the case of Microsoft.
\end{abstract}

\section{Introduction}

We define a base good' as one of two complimentary goods which must be purchased and installed prior to consume the supplemental goods, where a supplemental good' provides consumption benefit when only used in conjunction with the base good. A base good may give consumption benefit without supplemental goods but supplemental goods always require a base good. Markets that fit this basesupplemental goods description include: hardware - software, operating systemapplication software, and local phone- long distance service.

We narrow our focus in the current paper and consider the situation in which the base good market is monopolized and the supplemental goods are provided by two firms, one of which may be the base good monopolist. We assume that consmers have unit demands; i.e., they wish to purchase only one of the supplemental goods. For example, in the personal computer (PC) industry, the operating system (OS) is a base good, and application software programs are the supplemental goods. Microsoft monopolizes the PC operating system market, and competes with other firms in various application software markets; e.g., MS Word versus WordPerfect, Excel versus Lotus 1-2-3, and Internet Explorer versus Netscape Navigator.

In October 1997, the United States Department of Justice(DOJ) filed a lawsuit against Microsoft for violating an earlier consent decree which prohibited (among other things) bundling the Internet Explorer (IE) with the Windows operating system. The DOJ claims that bundling Internet Exporer with Windows is an anti-competitive move designed purely to drive Netscape out of the web browser business. The DOJ would like to force Microsoft to either remove its web browser from the Windows system or include a copy of Netscape Navigator with each sale of Windows 95. Meanwhile, Microsoft claims that

${ }^{1}$ Department of Justice, 'Petition by the United States to Show Cause Why Respondent Microsoft Corporation Should the consent decree allows them to integrate IE with Windows 95 since it benefits the consumers by giving them more choices at a lower price. ${ }^{2}$ Microsoft also argues that IE is an integrated part of its Windows system since Windows will not boot without IE. ${ }^{3}$

The DOJ's condemnation is based on the leverage theory', which says that bundling provides a mechanism whereby a firm with monopoly power in one market can use the leverage to monopolize a second market. However, the Chicago school has criticized leverage theory'and argued that the main motivation for bundling is price discrimination. Furthermore, they have argued that bundling could be socially beneficial, or at worst ambiguous behavior.

It is Whinston (1990) who revives the leverage theory of bundling. He shows that in the presence of scale economies and strategic interaction in the bundled good market, bundling can be a profitable strategy by driving bundled good market rivals out of the market. Whinston's model requires the exit of the rival firm for the profitability of bundling strategy. As Choi (1996) correctly points out, if competitor has already paid the sunk cost of entry and there is no avoidable fixed cost, bundling cannot be a profitable strategy. To overcome this problem, Choi considers the long run effects of $R \& D$ on competition. Consequently, his model results in foreclosures in the innovation market instead of the bundled good market.

The critical difference between the Chcago school literatures and recent leverage theory literatures comes from the market structure of the second market. Chicago school literatures assume that the second market is perfectly competitive, while Whinston (1990) assumes that the second market is not. We consider a duopoly supplemental good market, which is similar to Whinston. However, we find that without the exit of the rival firm, bundling strategy is profitable.

Not be Found in Civil Contempt," Antitrust Case Filings, 20 October, 1997 (http://www.usdoj.gov/art).

${ }^{2}$ Bill Gates, "US v. Microsoft: We're defending our right to innovate,” Wall Street Journal, 20 May, 1998.

3 Microsoft Corporation, "Memorandum of Microsoft Corporation in advance of the October 27, 1997 scheduling conference before the court," Microsoft Press Pass, 27 October, 1997 (http://www.microsoft.com/presspass).

${ }^{4}$ See Whinston_(1990) for the summary of Chicago school's argument. 
Bakos and Brynjolfsson (1998) show that bundling very large numbers of goods can be profitable if marginal production costs for goods are zero. The reason is that the law of large numbers makes it much easier to predict consumers' valuations for a bundle of goods than their valuations for the individual goods when sold separately, and as a consequence, the seller can extract higher consumer surplus. However, their basic setup is different from other literatures and ours because their single seller model has no consideration of competition, while we analyze the monopolist incentivesof bundling of second good in which market has serious competition.

Through base-supplemental relation, we analyze the incentives for a base-good monopolist to bundle a supplemental good with its platform, and determine the conditions under which this is an optimal strategy. We show that bundling a supplemental good with a base good is a profitable strategy for the base good monopolist, even without the exit of a supplemental good rival and without foreclosure of the supplemental good market. This is ourdifference from other leverage theory literatures. A bundling strategy increases the profit in the monopolized base good market.

The next question we analyze is the welfare implications. Specifically, is welfare lower (DOJ' belief) or higher (Microsoft's claim)? We find that the welfare effect of a bundling strategy depends on the degree of substitutability between the two competing supplemental goods. If two goods are close substitutes, then it decreases social welfare. Otherwise, a bundling behaviormay increase social welfare.

This paper is organized as follows. We describe the basic setting of our model in section 2. Section 3 analyzes the equilibrium prices and profits under three possible ownership structures. Section 4 explains whether or not firms have an incentive to merge and finds the equilibrium ownership structure. Section 5 examines the welfare implication of firms' mergers and pricing strategies. Section 6 provides a summary and conclusion.

\section{Basic Model}

There are three firms in this model: one firm (firm $\mathrm{B}_{\mathrm{n}}$ ) monopolizes the base good market and two firms (firm 1 and firm 2) produce supplemental goods ( $S_{1}$ and $S_{2}$, respectively). The marginal cost of producing a base good or a supplemental good is zero. As we will explain later, the zero marginal cost of a supplemental good is the critical assumption for our analysis. All fixed costs are sunk.

The tastes of consumers for the supplemental goods are uniformly distributed along the unit interval and the population is normalized to one. The locations of two supplemental good firms are fixed: firm 1 is located at $\mathrm{x}=0$ (leftend point) and firm 2 is located at $x=1$ (rightend point). A consumer incurs utility loss' which is proportional to the difference between the supplemental good and her taste. ${ }^{5}$

${ }^{5}$ Utility loss' in this mode 1 is similar to transportation cost' in linear city model (see Tirole(1988) Section 7.1).
When a consumer located at $\mathrm{x}$ purchases $\mathrm{S}$, her net benefit from consumption is

$$
\begin{aligned}
& V=u\left(B, S_{1}\right)-p_{S 1}-t x-p_{B} \\
& u\left(0, S_{i}\right)=0, \text { and } u\left(1, S_{i}\right)>0
\end{aligned}
$$

where $u\left(B, S_{1}\right)=u\left(B, S_{2}\right)$ is the utility from the supplemental good, $u(B, O)$ is the stand-alone benefit of the base good $\mathrm{B}, \mathrm{\beta}_{\mathrm{i}}$ is the price of supplemental good $\mathrm{S}, \mathrm{p}_{\mathrm{B}}$ is the price of the base good, and $\mathrm{t}$ is the degree of utility loss which represents the degree of differentiation between thesupplemental goods. For simplicity, we assume that $u(B, 0)=0$, which prevents a consumer from buying only a base good without purchasing a supplemental good in equilibrium. Finally, we assume that consumers have unit demand so each consumer either purchass zero or one unit of the good.

The supplemental goods are differentiated more for the consumers when $t$ is higher. As $t$ increases, both supplemental good firms have more monopoly powers. On the other hand, if $\mathrm{t}=0$, the two goods are identical, whichresults in the Bertrand competition with homogeneous goods.

A consumer located at $\mathrm{x}$ will buy $\mathrm{S}$ if

$$
\begin{aligned}
& u\left(B, S_{1}\right)-p_{S 1}-t x-p_{B}>u\left(B, S_{2}\right)-p_{S 2}-t(1-x)-p_{B} \quad \text { and } \\
& u\left(B, S_{1}\right)-p_{S 1}-t x-p_{B}>0
\end{aligned}
$$

Similarly, she will buy $\mathrm{S}_{2}$ if

$$
\begin{aligned}
& u\left(B, S_{2}\right)-p_{S 2}-t(1-x)-p_{B}>u\left(B, S_{1}\right)-p_{S 1}-t x-p_{B} \quad \text { and } \\
& u\left(B, S_{2}\right)-p_{S 2}-t(1-x)-p_{B}>0
\end{aligned}
$$

Finally, she wont buy anything if

$$
\begin{aligned}
& u\left(B, S_{1}\right)-p_{S 1}-t x-p_{B}<0 \text { and } \\
& u\left(B, S_{2}\right)-p_{S 2}-t(1-x)-p_{B}<0
\end{aligned}
$$

The game consists of three stages. $\mathrm{h}$ the first stage, the ownership structure is determined; the monopolist decides whether or not to merge with one or both of supplemental good firms. We assume that there is a transaction cost to change the ownership structure. In the second stage, the nonopolist sets the prices of its products, and consumers purchase and install the base goods. In the third stage, the remaining supplemental good firm(s) sets the price of the supplemental goods and consumers purchase them.

After the first stage, the owneship structure will be one of the following: 1) independent ownership, 2) partial integration, and 3) full integration. Under independent ownership, the monopolist sets $\mathrm{p}_{\mathrm{B}}$ in the second stage and supplemental good firms set $p_{S 1}$ and $p_{S 2}$ in the third stage. Under partial integration or full integration, the monopolist not only sets the price of the base good but also sets the price of the integrated supplemental good firm's product simultaneously. This gives a Stackelberg leader's advantage to the integrated firm.

Since the equilibrium outcome can be derived by backward induction, we first analyze the equilibrium prices and profits under three different ownership structures. 


\section{Three Ownership Structures}

\subsection{Independent Ownership}

To figure out the equilibrium outcome under independent ownership, we need to distinguish between the uncovered and covered markets. In other words, some consumers choose not to purchase goods in equilibrium under certain circumstances. Intuitively, one may think that the market is likely to be uncovered when $u\left(B, S_{i}\right)$ is small or the utility loss $t$ is large. Whether the market is covered or not is also affected by the firms' pricing strategy. The higher the price, the more likely it is to be uncovered. We start with theuncovered market case.

Since the market structure of two supplemental goods is symmetric under independent ownership, we consider only the demand for $S_{1}$ and the consumers located between zero and 1/2 when the market is uncovered. The demand function fo $\mathrm{S}_{1}$ and base good can be derived from the marginal consumer who is indifferent between purchasing both $\mathrm{B}$ and $\mathrm{S}$ and not buying anything. Therefore, from the marginal consumer's net benefit function $u\left(B, S_{1}\right)-p_{S I}-t x-p_{B}=0$, the demand for the two complementary goods $\mathrm{B}$ and $\mathrm{S}$, can be derived as

$$
x\left(p_{B}, p_{S 1}\right)=(1 / t)\left(u-p_{S 1}-p_{B}\right)
$$

where $u \equiv u\left(1, S_{i}\right), i=1,2$. Note that the demand function for $\mathrm{S}$ is not affected by the price of $\mathrm{S}$.

The monopolist's profit is $\pi_{B}\left(p_{B}, p_{S I}\right)=2 p_{B} x$, and firm 1's profit is $\pi_{l}\left(p_{B}, p_{S l}\right)=p_{l} x$. Since the monopolist is a Stackelberg leader, we can calculate the equilibrium outcome by substituting the response function of the supplemental firm into the monopolist's profit function. The response function is $p_{l}\left(p_{B}\right)=\left(u-p_{B}\right) / 2$, and the monopolist's profit function is $\pi_{B}\left(p_{B}, p_{S I}\left(p_{B}\right)\right)=p_{B}\left(u-p_{B}\right) / 2$. Therefore, we calculate the equilibrium outcome as follows.

$$
\begin{aligned}
& p_{B}{ }^{U, I}=u / 2 \\
& p_{S I} U, I=p_{S 2}{ }^{U, I}=u / 4 \\
& x^{U, I}=u /(4 t) \\
& \pi_{B}^{U, I}=u^{2} /(4 t) \\
& \pi_{I}^{U, I}=\pi_{2}^{U, I}=u^{2} /(16 t)
\end{aligned}
$$

Superscript U,I'stands for the uncovered market case under independent ownership. For (3) to be an equilibrium, $\mathrm{X}, \mathrm{I}$ must be less than $1 / 2$, and $t$ must be larger than $u / 2$. This implies a high degree of differentiation of the two supplemental goods.

Now, we need to find the optimal strategy of the firms when $t<u / 2$. In this situation the market is covered. If we consider the marginal consumer who is indifferent between purchasing $B$ and $S_{1}$ and purchasing $B$ and $S_{2}$, then the consumer's location $x$ is given by equating the costs for $\mathrm{S}$ and $\mathrm{S}_{2}$, i.e., $u\left(B, S_{1}\right)-p_{S I}$

\footnotetext{
${ }^{6}$ For this demand equation, we assume that $>0$. Otherwise, a marginal consumer does not exist.
}

- $t x-p_{B}=u\left(B, S_{2}\right)-p_{S 2}-t(1-x)-p_{B}$. Therefore, the demand function is $x\left(p_{S 1}, p_{S 2}\right)=\left(t-p_{S 1}+p_{S 2}\right) / 2 t$. By simultaneously solving the first order conditions of these two profit functions, we get the equilibrium prices and profits of the supplemental good firms. Once the supplemental goods' prices are derived, the base good price will be the price which makes the benefit of consumption equal to zero for the marginal consumer. However, this is not the optimal strategy for the monopolist. The problem for the monopolist is that this demand function excludes the base good price, so the monopolist is not able to act as a Stackelberg leader.

As a Stackelberg leader, the monopolist can set the base good price such that the marginal consumer is indifferent between buying $B$ and $S_{1}$, buying $B$ and $S_{2}$, or buying nothing. Recall the response function of a supplemental good firm isp $p_{i}\left(p_{B}\right)=\left(u-p_{B}\right.$ )/2. By substituting this into a consumer's benefit function and setting $\mathrm{p}_{\mathrm{B}}$ to make the benefit be zero for the consumer who is located at $x=1 / 2$, we can get the optimal strategy of the monopolist. Therefore, the optimal outcome in the covered market case under independent ownership is as follows:.

$$
\begin{aligned}
& p_{B}{ }^{C, I}=u-t \\
& p_{S I}{ }^{C, I}=p_{S 2}{ }^{C, I}=t / 2 \\
& x^{C, I}=1 / 2 \\
& \pi_{B}{ }^{C, I}=u-t \\
& \pi_{1}{ }^{C, I}=\pi_{2}{ }^{C, I}=t / 4
\end{aligned}
$$

Superscript C,I' represents the covered market case under independent ownership. From (3) and (4), we can conclude that the equilibrium outcome is(3) if $t \geq u / 2$ and is (4) if $t<u / 2$ under independent ownership.

\subsection{Partial Integration}

Now, we consider the case when the monopolist merges with firm 1. Equivalently, this may be the situation where the monopolist also provides one of the two supplemental products. This ownership structure is the current situation of Microsoft and Netscape in the OS and web browser market. In this case, $\mathrm{p}_{\mathrm{S} 1}$ is simultaneously determined with $\mathrm{B}$ in the second stage, while $\mathrm{p}_{\mathrm{S} 2}$ is still set in the third stage. Therefore, the integrated firm is now a Stackelberg leader while firm 2 is a Stackelberg follower. For the partial integration, once again, we consider the uncovered and covered market cases separately.

When the market is uncovered, the demand function for $\mathrm{B}$ and $\mathrm{S}_{1}$ is given as (2) and the demand for $B$ and $S_{2}$ is $\mathrm{y}\left(\mathrm{p}_{\mathrm{B}}, \mathrm{p}_{\mathrm{S} 2}\right)=(1 / t)$ $\left(u-p_{S 2}-p_{B}\right)$, where $y$ is the marginal consumer's distance from the right end point. In the second stage, the integrated firm sets $\mathrm{p}_{\mathrm{B}}$ and $\mathrm{p}_{\mathrm{S} 1}$ to maximize the joint profit $\pi_{B, I}=\left(p_{B}+p_{S 1}\right) x\left(p_{B}, p_{S I}\right)$ $+p_{B} y\left(p_{B}, p_{S 2}\right)$ and firm 2 sets $p_{S 2}$ to maximize the profit $\pi_{2}=p_{S 2}$ $y\left(p_{B}, p_{S 2}\right)$ in the third stage. The response function of firm 2 is $p_{2}\left(p_{B}\right)=\left(u-p_{B}\right) / 2$ which allows us to calculate the optimal outcome.

\footnotetext{
${ }^{7}$ In the independent ownership case, $x^{U, I}=y^{U, I}$.
} 


$$
\begin{aligned}
& p_{B}{ }^{U, P}=u / 2 \\
& p_{S 1} U, P=0, \quad p_{S 2}{ }^{U, P}=u / 4 \\
& x^{U, P}=u /(2 t), \quad y^{U, P}=u /(4 t) \\
& \pi_{B, I}{ }^{U, P}=3 u^{2} /(8 t) \\
& \pi_{2}^{U, P}=u^{2} /(16 t)
\end{aligned}
$$

Superscript U,P' represents the uncovered market under partial integration while subscript $\mathrm{B}, 1$ ' represents the integrated firm. The condition for the uncovered market is $x^{U, P}$ $<1-y^{U, P}$, which is $4 t>3 u$.

Now, suppose $4 t<3 u$, then the degree of differentiation of the two supplemental goods is relatively small so that the market is covered. The best strategy of the monopolist is to make the marginal consumer indifferent betweenbuying $B$ and $S_{1}$, buying $\mathrm{B}$ and $\mathrm{S}_{2}$, or buying nothing. We obtain the equilibrium outcome by using firm 2 's response function $p_{2}\left(p_{B}\right)=\left(u-p_{B}\right) /$ 2 and the marginal consumer's location constraint,

$$
\begin{aligned}
& x^{C, P}=1-y^{C, P} . \\
& p_{B}{ }^{C, P}=u-(2 / 3) t \\
& p_{S I}{ }^{C, P}=0, p_{S 2}{ }^{C, P}=t / 3 \\
& x^{C, P}=2 / 3, y^{C, P}=1 / 3 \\
& \pi_{B, 1}{ }^{C, P}=u-(2 / 3) t \\
& \pi_{2}{ }^{C, P}=t / 9
\end{aligned}
$$

Superscript C,P' represents the covered market under partial integration. From (5) and (6), we can conclude that under partial integration the equilibrium outcome is (5) if $4 t \geq$ $3 u$ and (6) if $4 t<3 u$.

The most interesting result is that the optimal price of: Sis zero $\left(\mathrm{p}_{S 1}=0\right)$ regardless of the coveredness of the market. The intuition why the integraed firm is better off by a zero price for the supplemental good is as follows. If firm 1 sets $\beta_{1}=0$, then firm 2 lowers $p_{S 2}$ because the two prices are strategic complements in a covered market. This enables the monopolist to charge a higher price forthe base good. The increase in profit from the base good market exceeds the reduction in profit from the supplemental good market. Therefore, when the market is covered, the source of gain is from the base good market. In the uncovered market, the integated firm is still better off. More consumers will purchase $\mathrm{B}$ and $\mathrm{S}_{1}$ because the total price has fallen. Cournot called this the elimination of double marginalization'.

However, a zero price of the supplemental good cannot guarantee the optimal outcome, due to the time inconsistency problem. The integrated firm announces $\mathrm{B}_{1}=0$ in the second stage and sells $S_{1}$ in the third stage. If consumers believe $\beta_{1}=0$, then those who have purchased the base goods with price $\mathrm{B}^{\mathrm{C}, \mathrm{P}}$ would buy either $S_{1}$ or $S_{2}$ in the third stage. Once the integrated firm has sold the base good, however, it would be better off selling $S_{1}$ with positive price in the third stage. The optimal renegotiation price is $p_{S 1}=t / 3$ when the market is covered and $\mathrm{p}_{\mathrm{S} 1}=\mathrm{u} / 4$ when the market is uncovered. In this case, some portion of consumers who have already purchased the base goods will not buy the supplemental goods.

One way to solve this problem is to sell $\mathrm{S}$ together with the base good in the second stage. This is called a bundling strategy'. Therefore, we conclude that the optimal strategy of the integrated firm under partial integration is a bundling strategy'. However, this result is not robust to a nonzero marginal cost. If the marginal production cost of the supplemental good is cand $\mathrm{c}>0$, then $p_{S I}^{U, P}=c$ and $p_{S I}{ }_{S I}^{C, P}=c / 2$. Since the zero price of the supplemental good is a necessary condition for the bundling strategy, bundling can not be the optimal strategy of the integrated firm under a nofzero marginal cost.

In the software industry, it is commonly believed that the marginal production cost is zero. Therefore, if the supplemental good is a software, we assert that the optimal strategy of the integrated firm is to bundle a supplemental good with base good.

Another interesting result is that the rival firm can still capture a significant portion of market in spite of bundling. When two supplemental goods are not close substitutes (when $\mathrm{t}$ is large), this is not a surprising result, because switching from $S_{2}$ to $S_{1}$ causes big utility loss to the consumers locating near the right end point. However, even if two goods are very close substitutes, so the value of $t$ is very small, the rival firm still obtains one-third of the market share. This is because the rival supplemental good price is also close to zero when two goods are close substitutes. The bundling strategy will not force the rival firm to exit the market.

Whinston (1990) and Choi (1996) argue that bundling is profitable strategy because it drives the rival firm out ofthe market. However, in our static model, it is still profitable even without the exit of rival firm, because it increases profits in the base good market. ${ }^{8}$ We can claim the following proposition.

<Proposition 1> When the marginal production cost of a supplemental good is zero, bundling' the supplemental good with the base good is the optimal strategy of the integrated firm. The rival firm will not be driven out of the market by a bundling strategy regardless of the degree of differentiation of two supplemental goods. However, a bundling strategy increases profits in the base good market.

This proposition has three arguments. The first one is that the integrated firm's optimal strategy is bundling strategy, the second one is that the rival firm retains significant market share in spite of bundling strategy, and the third one is that the purpose of the bundling strategy is to increase profit in the base good

${ }^{8}$ One may insist that the integrated firm does not increase profits in base good market but simply changes the timing of collection of profits in the supplemental good. We show that the integrated firm does increase profits in base good market in the Appendix. 
market. The first two arguments do not need further proofs and we need to show only the last one.

As we will show in the next proof, $\pi_{B, I}{ }^{C, P}$ is larger than $\pi_{B}{ }^{C, I}$ $+\pi_{l}^{C, I}$. If we consider the profits from the sales to consumers who used $S_{1}$ under independent ownership, i.e., $x<1 / 2$, then the integrated firm has smaller profit under patial integration than independent ownership because $\left(\pi_{B, 1}{ }^{C . P}\right) / 2=u / 2-t / 3$ is smaller than $\left(\pi_{B}{ }^{C, I}\right) / 2+\pi_{I}{ }^{C, I}=\mathrm{u} / 2-\mathrm{t} / 4$. The reason for $\pi_{B, I}{ }^{C, P}>\pi_{B}{ }^{C, I}$ $+\pi_{I}^{C, I}$ is, then, that the profits from the sales of the base good to the consumers with $S_{2}$ i.e, $x>1 / 2$ are increased under partial integration. Therefore, we can say that the result of bundling strategy is to increase the profit in the base good market

\subsection{Full Integration}

The final ownership structure we analyze is the case when all firms are integrated. Here, the integrated firm sets $\mathrm{\beta}_{1}, \mathrm{p}_{\mathrm{S} 2}$, and $\mathrm{p}_{\mathrm{B}}$ to maximize the joint profit in the second stage. If the market is uncovered, the equilibrium outcome is as follows.

$$
\begin{aligned}
& p_{B}{ }^{U, F}=u / 2-p_{S 1}^{U, F} \\
& p_{S 1}{ }^{U, F}=p_{S 2} U, F \\
& x^{U, F}=y^{U, F}=u /(2 t) \\
& \pi_{B, 1,2}{ }^{U, F}=u^{2} /(2 t)
\end{aligned}
$$

Superscript U,F' represents the uncovered market with full integration, and subscript $\mathrm{B}, 1,2^{\prime}$ is the merger of all three firms.

The condition for the uncovered market is $x^{U, F}<1-y^{U, F}$, which implies $t>u$. If the utility loss is relatively small so that $t<u$, then the equilibrium outcome is as follows.

$$
\begin{aligned}
& p_{B}{ }^{C, F}=u-p_{S 1}^{C, F}-t / 2 \\
& p_{S 1}^{C, F}=p_{S 2}^{C, F} \\
& x^{C, F}=y^{C, F}=1 / 2 \\
& \pi_{B, 1,2}{ }^{C, F}=u-t / 2
\end{aligned}
$$

Superscript C,F' represents the covered market under full integration.

From (7) and (8), we can say that under full integration the equilibrium outcome is (7) if $t \geq u$, and (8) if $t<u$. Note that there is no unique solution for prices in this full integration case. As long as prices satisfy the equations in (7) or (8), they can be equilibrium prices. However, just like the partial integration case, the integrated firm confronts a time imonsistency problem. One familiar solution to this problem is to bundle the two supplemental goods with the base good. The price of the bundled package is $u / 2$ and $u-t / 2$ from (7) and (8) respectively.

\section{Equilibrium Ownership Structure ${ }^{9}$}

\footnotetext{
${ }^{9}$ We don't consider the horizontal mergers between two supplemental good firms. It is easy to show that there is no incentive for horizontal mergers in our model. When the market is uncovered, two supplemental good prices are not interdependent, and as a result here is no gain from horizontal
}

To check whether firms have an incentive to merge, we must compare the profits of firms under various ownership structures. As we suggested in the previous section, the subgame outcome depends on the relative magnitude of the utility loss and consumption benefit of the gøds. Therefore, we consider four possible cases: (a) $t<u / 2$, (b) $u / 2 \leq t<$ (3/4) $u$, (c) (3/4) $u \leq t$ $<u$, and (d) $u \leq t$. The degree of differentiation between the two supplemental goods is smallest in case (a) and largest in case (d). Or, we can say that the closeness of substitutability between the two supplemental goods is the highest in case (a) and the lowest in case (d). In this section, we check the incentives for merger.

We first assume that transaction costs are negligible. We consider the case when $t<u / 2$, so two supplemental goods are very close substitutes. In this case, the market is covered regardless of ownership structure. Suppose the initial ownership structure is an independent ownership. By comparing the profit of the firms in 4) and (6), we can determine if there is an incentive for partial integration. We conclude that the monopolist will merge with firm 1 because $\pi_{B}$ ${ }^{\mathrm{C}, \mathrm{I}}+\pi_{1}{ }^{\mathrm{C}, \mathrm{I}}<\pi_{B, 1}{ }^{\mathrm{C}, \mathrm{P}}$ (see Appendix for the proof of proposition 2). We also find that firm 2 realizes a rediction in profit under partial integration. Next, we compare the profit in (6) and (8) to determine if firms are better off under full integration. We find that the fully integrated firm's profit in (8) is greater than the sum of the profits in (6), so frms are better off under full integration.

Note that the joint profit of the integrated firm is the same as the sum of three independent firms' profits. There is no reason to change from independent ownership to full integration. The equilibrium structure is full integration when transaction costs are small. Under independent ownership, there is an incentive for partial integration, and under partial integration there is an incentive for full integration. ${ }^{10}$

A similar analysis applies to other cases. If the utility loss is in the range $u / 2 \leq t<(3 / 4) u$, then the market is uncovered under independent ownership yet covered under partial integration or full integration. Therefore, (3), (6), and (8) are compared. Like the previous case, we find that th monopolist has an incentive to merge with firm 1 while firm 2 is hurt by this partial merger. We also find an incentive for full integration.

Next, if(3/4) $u \leq t<u$, then the market is covered only under

integration. When the market is covered, the horizontally merged firm's optimal strategy is to split the market half and half, which is the same strategy before the merger. Clearly, there is no incentive for horizontal interation.

10 If we consider the division of integrated profit among the original individual firms, then because of the negotiation power, each supplemental good firm earns as much as the unintegrated rival supplemental good firm's profit under partial integration $(t / 9)$ and the monopolist gets the residual surplus. However, the division of profits of integrated firm is of little interest to us. 
full integration while uncovered under other stuctures. We compare (3), (5), and (8). There is an incentive for the base good monopolist and firm 1 to integrate. Note that firm 2's profit is not affected by this merger contrary to the two previous cases. Firms have higher profits under full integation than under partial integration.

Finally, when $u \leq t$, so the differentiation of two supplemental goods is very large, then the market remains uncovered under any ownership structure. We compare (3), (5), and (7) and find an incentive for a monopolist to merge one of the two supplemental good firms. All firms are also better off under full integration.

We can conclude with the following proposition.

<Proposition 2> When the transaction costs of mergers are negligible, the equilibrium structure of ownership is always full integration.

\section{Proof: See Appendix}

Now, let's introduce positive transaction costs of mergers in our model. The equilibrium ownership structure is determined by the relative magnitude of transaction costs and gains from integrations. For example, when $t<u / 2$, so when the market is covered, the gain of partial integration ist/12, while the gain of full integration is $t / 18$. If the transaction cost is smaller than $t / 18$, then full integration is an equilibrium. If the transaction cost is between $t / 18$ and $t / 12$, then partial equilibrium is an equilibrium. Finally, if the transaction cost is larger thant/12, then any initial structure is the equilibrium.

For all other cases, the gain of partial integration is greater than the gain offull integration with the exception of the case $t$ $\geq u$. When $t \geq u$, the two gains are equal. Therefore, we propose that the gain of partial integration is greater than or equal to the gain of full integration (see the proof in Appendix).

<Proposition 2'> Since the profit gain of partial integration is not smaller than that of full integration, the equilibrium structure is partial integration if the cost is smaller than the partial integration gain and larger than the full integration gain. It the cost is smaller than the full integration gain, then the full integration is the equilibrium. If the cost is larger than the partial integration gain, then the initial structure is the equilibrium.

Proof: See Appendix

\section{Welfare Analysis}

Since welfare is consumer surplus plus profits, we need to compute consumer surplus for each case. Consumer surplus is the summation of a consumer's net benefit. Therefore, consumer surplus is

$$
\int_{0}^{x^{*}}\left(u-p_{s_{1}}-t x-p_{B}\right) d x+\int_{0}^{y^{*}}\left(u-p_{s_{2}}-t y-p_{B}\right) d y,
$$

where $\mathrm{x}$ is the distance from the left end point, ysi the distance from the right end point, and $\mathrm{x}^{*}$ and $\mathrm{y}^{*}$ represent the locations of marginal consumers. Computed welfare for (3), (4), (5), (6), (7), and (8) are as follows.

$$
\begin{aligned}
& W F^{U, I}=7 u^{2} /(16 t) \\
& W F^{C, I}=u-t / 4 \\
& W F^{U, P}=19 u^{2} /(32 t) \\
& W F^{C, P}=u-(5 / 18) t \\
& W F^{U, F}=3 u^{2} /(4 t) \\
& W F^{C, F}=u-t / 4
\end{aligned}
$$

We consider the four different cases (as we did in the previous section) to determine the welfare effect of integrtion and pricing strategy. For the welfare analysis, we assume that the transaction costs are negligible for simplicity. First, we concentrate on the welfare effect of partial integration. Under partial integration, we have already showed that the integated firm's optimal strategy is to bundle the supplemental good with the base good.

For case (a), in the previous section, $t<u / 2$, the integrated firm charges a lower price for the bundled goods than under independent ownership. So, the consumers whobuy B and $S_{1}$ under independent ownership are better off. Although $B_{2}$ is lower, because $\mathrm{p}_{\mathrm{B}}$ is higher, consumers who purchase B and $\mathrm{S}_{2}$ pay more. Besides the consumers who switch from $\mathbf{S}$ to $S_{1}$ incur higher utility loss. The reduced profit of firm 2 is als larger than the increased profit of the integrated firm. The negative effects are unambiguously larger than the positive effects, hence, a partial merger and bundling strategy reduce welfare.

For case (b), $u / 2 \leq t<(3 / 4) u$, consumers with $\mathrm{B}$ and $\mathrm{S}_{1}$ are better off while consumers with $\mathrm{B}$ and $\mathrm{S}$ pay more. The total welfare effect which includes utility and profits cannot be unambiguously determined. If the utility loss is relatively small $(t<0.510 u)$, then we have welfare loss. Contrarily if $>0.510$ $u$, then partial integration and bundling strategy are welfare enhancing.

Finally, for case (c) or (d), $(3 / 4) u<t$, the market is uncovered in both cases. Consumers with B and $\mathrm{S}$ are better off due to a lower total price while consumers with $\mathrm{B}$ and $\mathrm{S}$ are indifferent because the bundling strategy does not affect firm 2 . The integration brings only the elimination of double marginalization. So, the partial integration and bundling strategy are always welfare enhancing. Therefore, we can conclude as follows.

<Proposition 3> Partial integration and bundling strategy reduce welfare when two supplemental goods are close substitutes $(t \leq 0.510 u)$. If the degree of differentiation of two goods is quite high, then partial integration and bundling strategy have welfare enhancing results $(t>0.510 u)$. 


\section{Proof: See Appendix}

Now, we check the welfare effect of full integration. For case remaining rival firm (Netscape) would increase social welfare (a), full integration restores welfare to the level under even higher. independent ownership. Therefore, society would be better off by full integration in this case. For other cases, it is straightforward to show that welfare under full integration is greater than under partial integration. Firms' total profits are higher under full integration (recall that firm's always have incentives for full integration) and consumers with $\mathrm{B}$ and $\mathrm{S}$ are better off by a lower joint price. Only some portion of consumers with $B$ and $S_{\perp}$ who previously enjoyed the benefit of partial integration are worse off. The latter effect is overwhelmed by the former efect. Besides, welfare under full integration is the largest among three possible ownership structures. The distortion of an economy may be the smallest under full integration.

<Proposition 4> If the market is covered regardless of ownership structure, then welfare under full integration is equal to that of independent ownership. In all other cases, full integration brings the highest social welfare among the three ownership structures

Proof: See Appendix

$$
\text { 6. Conclusion }
$$

We have shown that to bundle a supplemental good with a base good is the optimal pricing strategy of the base good monopolist who also supplies supplemental goods. Without the exit of rival supplemental good firm, the bundling is profitable because it increases the profits in the basegood.

We have also shown that the bundling strategy reduces social welfare as well as rival firm's profit if the two supplemental goods are close substitutes. The rival firm still retains a significant market share even in this case. Therefore, contrary to the DOJ's argument, Microsoft (the base good monopolist) does not become a supplemental good (web browser) monopolist simply by bundling IE with Windows. Moreover, a bundling strategy is not always harmful for society. When two [7] supplemental goods are not close substitutes, we have shown that bundling strategy may increase welfare. The equilibrium ownership structure depends on the transaction costs of mergers and the initial structure.

Finally, we may carefully think about the political implication. On the belief that Microsoft is leveraging its monopoly power of OS market to other supplemental goods markets, some people insist that the government should split Microsoft into a base good firm and supplemental good firms.

${ }^{11}$ For example, the Silicon Valley Research Institute (SRI) proposes dividing Microsoft into five different companis calling them "Baby Softs". This is analogous to the divestiture of the telecommunication monopoly AT\&T (The New York Times, May 25, 1998).
This may increase social welfire if the divestiture is not too costly. According to our model, however, the merger with the As we mentioned earlier, the DOJ would like to force Microsoft either to remove its web browser from Windows packages or to include a browser made by rival Netscape. One may think that removing Internet Explorer from Windows is the easiest solution. However, this might not be the best solution. Suppose the monopolist can commit to a sipplemental good price when it sells the base good. If the monopolist wants to build its reputation over time, so the commitment is binding, then it can attain the same profit as bundling strategy by announcing $p_{S_{1}}=0$. To increase social welfare, ironicaly, the government could set a price floor by removing the product from the package. Contrarily, including the rival's product in the package might be a solution by itself, because this brings the same welfare results as under full integration. The onlyproblem is the division of profit, i.e., at what price the monopolist buys the rival's product, which is beyond the scope of this work.

\section{REFERENCES}

[1] Bakos, Y. and Brynjolfsson E., (1998): "Bundling Information Goods: Pricing, Profits, and Efficiencÿ, memeo.

[2] Carlton, D. and Waldman, M., (1998): "The Strategic Use of Tying to Preserve and Create Market Power in Evolving Industries," mimeo.

[3] Choi, J. (1996): "Preemptive R\&D, Rent Dissipation, and the Leverage Theory," The QuarterlyJournal of Economics, 114(4), 1153-1181.

[4] Choi, J. and S. Yi (1997): "Vertical Foreclosure with the Choice of Input Specifications," mimeo.

[5] Church, J. and N. Gandal (1997): "System Competition, Vertical Merger and Foreclosure," mimeo.

[6] Economides, N. and S. Salop (1992): "Competition and Integration among Complements, and Network Market Structure," Journal of Industrial Economics, XL(1), 105-33.

[7] Economides, N. (1994): "The Incentive for Vertical Integration," Discussion Paper EC-94-05, Stern School of Business, N.Y.U.

(1997): "The Incentive for Non-price discrimination by an Input Monopolist," Center for Economic Policy Research(CEPR) Publication No.486. (1998): "Raising Rival's Costs in Complementary Goods Markets: LECs Emering into Long Distance and Microsoft Bundling Internet Explorer," forthcoming in the Annual PRC 1997 Volume.

[10] Frazer, Tim (1988): Monopoly, Competition and the Law, St. Martin's Press, New York.

[11] Fisher, F.M., J. McGowan and J. Greenwook (1983) Folded, Spindled, and Multilated: Economic Analysis and U.S. v. IBM, MIT Press, Cambridge, Massachusetts. [12] Lee, S. (1998) : "Vertical Merger and Compatibility in 
Base-Supplemental Goods Industries," mimeo.

[13] Ordover, J. G. Saloner, and S. Salop (1990): 'Equilibrium Vertical Foreclosure," American Economic Review, 80(1), 127-42.

[14] Tirole, J. (1988): The theory of Industrial Organization, The MIT press, Cambridge.

[15] Whinston, M.D., (1990): "Tying, Foreclosure, and Exclusion," American Economic Review, 80, 837-859

\section{Appendix}

\section{Proof of Proposition 2}

We need to show i) $\pi_{B}{ }^{I}+\pi_{1}{ }^{I}<\pi_{B, 1}{ }^{P}$ and ii) $\pi_{B, 1}{ }^{P}+\pi_{2}^{P}<$ $\pi_{B, 1,2}{ }^{F}$ for all four cases of utility loss. Case (a), $\mathrm{t}<\mathrm{u} / 2$. i $\pi_{B}{ }_{C, I}$ $+\pi_{l}^{C, I}=u$-(3/4) $t$ is smaller than $\pi_{B, I}{ }^{C, P}=u-(2 / 3) t$ and ii) $\pi_{B, I}{ }^{C, P}$ $+\pi_{2}^{C, P}=u$-(5/9)t is also smaller than $\pi_{B, 1,2}{ }^{C, F}=u-t / 2$. Therefore, i) and ii) hold for this case. Case (b), when $\mathrm{t}$ is between $\mathrm{u} / 2$ and (3/4)u. i) $\pi_{B}{ }^{U, I}+\pi_{I}^{U, I}=5 u^{2} /(16 t)$ and $\pi_{B, I}{ }_{C, P}$ $=u-(2 / 3) t .5 u^{2} /(16 t)$ is smaller than $u-(2 / 3) t$ if and only if $\frac{6-\sqrt{6}}{8} u<t<\frac{6+\sqrt{6}}{8} u$, which approximates as $0.444 u<t<$ $1.056 u$. Since $u / 2 \leq t<(3 / 4) u$, we can say that $5 u^{2} /(16 t)$ is smaller than $u-(2 / 3) t$ for this range of $t$. ii) see (a)-ii. Therefore, i) and ii) hold for this case.

Case (c), when $\mathrm{t}$ is between $(3 / 4) \mathrm{u}$ and $\mathrm{u}$. i) $\pi_{B}{ }^{U, I}+\pi_{l}^{U, I}$ $=5 u^{2} /(16 t)$ is smaller than $\pi_{B, I} U, P=3 u^{2} /(8 t)$. ii) $\pi_{B, I}^{U, P}+$ $\pi_{2}^{U, P}=7 u^{2} /(16 t)$ and $\pi_{B, 1,2}{ }^{C, F}=u-t / 2 . \quad 7 u^{2} /(16 t)$ is smaller than $u-t / 2$ if and only if $\frac{4-\sqrt{2}}{4} u<t<\frac{4+\sqrt{2}}{4} u$, which approximates as $0.646 u<t<1.354 u$. Since $(3 / 4) u \leq t<u$, we can say that $7 u^{2} /(16 t)$ is smaller than $u$-t/2 for this range of utility loss. Therefore, i) and ii) hold for this case.

Case (d), when $\mathrm{t} \geq \mathrm{u}$. i)we already showed this in the above (c)-i). ii) $\pi_{B, 1}^{U, P}+\pi_{2}^{U, P}=7 u^{2} /(16 t)$ is smaller than $\pi_{B, 1,2} U, F=$ $u^{2} /(2 t)$. Therefore, i) and ii) hold for this case. From the four cases (a), (b), (c), and (d), we conclude that $\pi_{B}{ }^{I}+\pi_{I}{ }^{I}<\pi_{B, I}{ }^{P}$ and $\pi_{B, 1}{ }^{P}+\pi_{2}{ }^{P}<\pi_{B, 1,2}{ }^{F}$. Hence, the equilibrium structure of ownership is always full integration when the transation costs of mergers are negligible. <Q.E.D.>

\section{Proof of Proposition 2'}

All we need to show for this proposition is that the profit gain of partial integration is not smaller than the profit gain of full integration. For case (a), the gain of partial integration is $t / 12$, while the gain of full integration is $t / 18$. Therefore, the proposition holds for this range of utility loss. For case (b), the gain of partial integration is $u-(2 / 3) t-5 u^{2} /(16 t)$, while the gain of full integration is $/ 18$. The former is larger than the latter if and only if $\frac{36-3 \sqrt{14}}{52} u<t<\frac{36+3 \sqrt{14}}{52} u$, which approximates as $0.476 u<t<0.908 u$. Since $u / 2 \leq t<(3 / 4) u$, this inequality is true for this case. Therefore, the proposition holds for this range of utility loss. For case(c), the gain of partial integration is $\mathrm{u}^{2} /(16 \mathrm{t})$, while the gain of full integration is $u-t / 2-7 u^{2} /(16 t)$. The former is always larger than the latter because the difference of the two is $(t-u)^{2} / 2$ Therefore, the proposition holds for this range of utility los. For case(d), both the gain of partial integration and the gain of full integration $\operatorname{are} u^{2} /(16 t)$. From (a), (b), (c), and (d), we conclude that the profit gain of partial integration is larger than or equal to the profit gain of full integration. <Q.E.D.>

\section{Proof of Proposition 3}

We need to compare welfare under independent ownership and welfare under partial integration. For case (a), so when < $u / 2, W F^{C, I}=u-t / 4$ is larger than $W F^{C, P}=u-(5 / 18) t$. For case (b), so when $u / 2 \leq t<(3 / 4) u, W F^{U, I}=7 u^{2} /(16 t)$ and $W F^{C, P}=$ $u-(5 / 18) t$. The former is smaller than the latter if and only if $\frac{36-3 \sqrt{74}}{20} u<t<\frac{36+3 \sqrt{74}}{20} u$, which approximates as $0.510 u<t$ $<83.614 u$. Since we consider the utility loss between $\mathrm{u} / 2$ and $(3 / 4) \mathrm{u}$, we can say that $W F^{U, I}>W F^{C, P}$ if $u / 2 \leq t \leq 0.510 u$, and $W F^{U, I}<W F^{C, P}$ if $0.510 u<t<(3 / 4) u$. For case (c) and case (d), $W F^{U, I}=7 u^{2} /(16 t)$ is smaller than $W F^{U, P}=19 u^{2} /(32 t)$.

Therefore we conclude that partial integration causes welfare loss if $t \leq 0.510 u$, so if two supplemental goods are close substitutes. If $t>0.510 u$, then partial integration is welfare enhancing. <Q.E.D.>

\section{Proof of Proposition 4}

For case (a), it is trivial to show that $W F^{C, I}=W F^{C, F}>W F^{C, P}$ For other cases, we need to show that the welfare under full integration is the largest. For case (b), all we need to check is whether $W F^{U, I}<W F^{C, F}$ or not. This inequality holds if and only if $u / 2<t<(7 / 2) u$. Since $u / 2<t<(3 / 4) u$, this is true for this case. For case (c), since we showed that $W F^{U, I}<W F^{U, P}$ in the previous proposition, we need to show that $W F^{U, P}<W F^{C, F}$. This inequality holds if and only if $\frac{8-\sqrt{26}}{4} u<t<\frac{8+\sqrt{26}}{4} u$, which approximates $0.725 u<t<3.275 u$. This is true because we are considering the case when $(3 / 4) u<t<u$. For case (d), it is easy to show that $W F^{U, I}<W F^{U, P}<W F^{U, F}$. From (b), (c), and $(\mathrm{d})$, we conclude that the full integration brings the highest social welfare. <Q.E.D.> 